\title{
Patiromer Decreases Serum Potassium and Phosphate Levels in Patients on Hemodialysis
}

\author{
David A. Bushinsky ${ }^{a}$ Patrick Rossignol ${ }^{b}$ David M. Spiegel ${ }^{c}$ Wade W. Benton $^{c}$ \\ Jinwei Yuan ${ }^{c}$ Geoffrey A. Block ${ }^{d}$ Christopher S. Wilcox ${ }^{e}$ Rajiv Agarwal ${ }^{f}$ \\ ${ }^{a}$ Department of Medicine, University of Rochester, Rochester, N.Y., USA; ${ }^{b}$ Inserm, Centre d'Investigations \\ Cliniques-Plurithématique, Université de Lorraine, Association Lorraine de Traitement de l'Insuffisance Rénale, \\ and F-CRIN INI-CRCT (Cardiovascular and Renal Clinical Trialists), Nancy, France; ' Relypsa, Redwood City, Calif., \\ ${ }^{d}$ Denver Nephrologists, Denver, Colo., e Department of Medicine, Georgetown University, Washington, D.C., and \\ fDepartment of Medicine, Indiana University School of Medicine, Indianapolis, Ind., USA
}

\section{Key Words}

Patiromer · Hemodialysis · Potassium · Phosphate ·

Hyperkalemia $\cdot$ End-stage renal disease

\begin{abstract}
Background: Persistent hyperkalemia (serum potassium (K) $\geq 5.5 \mathrm{mEq} / \mathrm{l})$ is a common condition in hemodialysis (HD) patients, is associated with increased mortality, and treatment options are limited. The effect of patiromer, a gastrointestinal $\mathrm{K}$ binder, on serum K was examined in HD patients. Methods: Six hyperkalemic HD patients (5 anuric) were admitted to clinical research units for 15 days ( 1 pretreatment week and 1 patiromer treatment week) and they received a controlled diet with identical meals on corresponding days of pretreatment and treatment weeks. Phosphate $(\mathrm{P})$ binders were discontinued on admission. Patiromer, $12.6 \mathrm{~g}$ daily (divided $4.2 \mathrm{~g}$ TID with meals), was started on the Monday morning following the last pretreatment week blood sampling. Serum and 24-hour stool samples were collected daily. Results: Mean \pm SE serum $\mathrm{K}$ decreased (maximum change per corresponding day, $0.6 \pm 0.2 \mathrm{mEq} / \mathrm{l}, \mathrm{p}=0.009$ ) and fecal $\mathrm{K}$ increased $58 \%$ on patiromer compared with the pretreatment week. During the pretreatment week, 69.0, 47.6, and $11.9 \%$ of patients' serum $K$ values were $\geq 5.5, \geq 6.0$, and $\geq 6.5$
\end{abstract}

\section{KARGER}

E-Mail karger@karger.com www.karger.com/ajn

\section{C) 2016 The Author(s) \\ Published by S. Karger AG, Basel 0250-8095/16/0445-0404\$39.50/0}

This article is licensed under the Creative Commons AttributionNonCommercial-NoDerivatives 4.0 International License (CC BYNC-ND) (http://www.karger.com/Services/OpenAccessLicense). Usage and distribution for commercial purposes as well as any distribution of modified material requires written permission.
$\mathrm{mEq} / \mathrm{l}$, respectively. This was reduced to $38.1 \%(\mathrm{p}=0.009)$, $11.9 \%(p<0.001)$, and $2.4 \%(p=0.2)$ on patiromer. Following $P$ binder discontinuation, the long interdialytic interval mean \pm SE serum $P$ numerically increased from $5.8 \pm 0.4$ to $7.0 \pm 0.5 \mathrm{mg} / \mathrm{dl}(p=0.06)$. On patiromer, $P$ decreased from $7.0 \pm 0.5$ to $6.2 \pm 0.5 \mathrm{mg} / \mathrm{dl}(p=0.04)$. While on patiromer, fecal $P$ numerically increased by $112 \pm 72 \mathrm{mg} /$ day $(17 \% ; \mathrm{p}=$ 0.1792 ; range -148 to $344 \mathrm{mg} /$ day). No patient discontinued patiromer because of adverse events (AEs); none had serious AEs. Conclusions: In 6 hyperkalemic HD patients, patiromer decreased serum $\mathrm{K}$ and $\mathrm{P}$ levels and increased fecal $\mathrm{K}$.

(c) 2016 The Author(s)
Published by S. Karger AG, Basel

\section{Introduction}

Hyperkalemia is a common condition found in chronic hemodialysis (HD) patients, being present in nearly $20 \%$ of routine laboratory results from large dialysis providers [1]. While often viewed as acute or episodic, these increases in serum potassium $(\mathrm{K})$ appear to reflect oscil-

ClinicalTrials.gov registration: NCT02033317.
David A. Bushinsky, MD

John J. Kuiper Distinguished Professor of Medicine and Physiology Chief, Nephrology Division, University of Rochester Medical Center 601 Elmwood Ave., Box 675, Rochester NY 14642 (USA)

E Mail David_Bushinsky@URMC.Rochester.edu 
lations above a persistent hyperkalemia baseline [2]. Numerous observational studies in HD patients have reported an association between elevated K levels and increased morbidity and mortality $[1,3]$. The increased event rate, and particularly sudden death, observed in the HD population is not evenly distributed over the 7-day week but is clustered toward the end of the long interdialytic interval and the immediate post dialysis period [4]. These data raise the possibility that hyperkalemia occurring during the long interdialytic interval and the acute decreases in the serum $\mathrm{K}$ concentrations induced by the HD procedure may play a role in the increased event rate and mortality seen in HD patients.

Patiromer is an FDA-approved, sodium-free, nonabsorbed K-binding polymer shown to reduce serum Klevels in patients with chronic kidney disease (CKD), with and without heart failure [5-8]. Patiromer exchanges calcium (Ca) for $\mathrm{K}$ in the gastrointestinal tract, primarily in the colon where active $\mathrm{K}$ secretion occurs, the $\mathrm{pKa}$ of patiromer is optimal for ion exchange, and the polymer has the longest residence time [9-11]. This phase 2 study was performed early in the clinical development program following studies in healthy volunteers. The primary objective of this study was to assess the efficacy of patiromer in reducing the serum $\mathrm{K}$ in $\mathrm{HD}$ patients and to evaluate the safety and tolerability of patiromer in this patient population.

\section{Methods}

The study protocol was reviewed and approved by an institutional review board (Copernicus Group, Research Triangle Park, N.C., USA) and written informed consent was obtained from each patient prior to enrollment. The study was conducted in accordance with the ethical principles of the Declaration of Helsinki and in accordance with International Conference on Harmonization/ Good Clinical Practice guidelines.

Six patients were enrolled and admitted to the clinical research unit at 2 sites (Minneapolis, Orlando) on a Sunday and they remained confined throughout the 2 -week study (1 pretreatment week and 1 patiromer treatment week). Patients received 3 times per week HD and were required to have a serum $K \geq 5.5 \mathrm{mEq} / \mathrm{l}$ and a $\mathrm{Kt} / \mathrm{V} \geq 1.2$ for entry into the study. All patients were on a stable dialysis prescription, including a stable dialysate K prior to admission and remained on that same prescription throughout the study. All patients were dialyzed on a Monday-Wednesday-Friday schedule and received treatment approximately the same time of day throughout the study. On admission, patients were placed on a $\mathrm{K}$-, magnesium (Mg)-, $\mathrm{Ca}$-, and $\mathrm{Na}$-controlled diet throughout the study period with identical meals on corresponding days of the pretreatment and patiromer treatment weeks. It was essential that dietary intake remained unchanged from the time of screening through the end of study participation. No food or drink other than that provided by the Clinical Research Unit was con-

Patiromer Decreases Serum K and P levels in HD sumed during the entire study period. On average, the daily K-, $\mathrm{Mg}-, \mathrm{Ca}-$, and $\mathrm{Na}$-controlled diet provided the following micronutrients (mean $\pm \mathrm{SE}$ ): K 2,760 $\pm 60 \mathrm{mg}, \mathrm{Na} 2,692 \pm 93 \mathrm{mg}$, Ca $619 \pm$ $22 \mathrm{mg}, \mathrm{Mg} 225 \pm 27 \mathrm{mg}$. Any unconsumed food was recorded.

$\mathrm{P}$ binders, Ca supplements, and the polymer-based medications colesevelam and colestipol were discontinued on admission and along with commercially available K-binding resins were not allowed during the study period. No subject had received sodium polystyrene sulfonate (SPS) in the 30 days preceding study entry. All treatments were administered in the Clinical Research Unit under the supervision of clinical personnel.

Serum chemistries were measured on a daily basis (pre-HD on HD days). Serum bicarbonate was not measured during the course of the study. Only 1 patient produced more than $200 \mathrm{ml}$ of urine per day and the ionic content of the urine was not analyzed. Twenty-four-hour stool samples were collected during the entire confinement period. Each 24-hour fecal collection was homogenized and aliquots were then analyzed for $\mathrm{K}, \mathrm{Na}, \mathrm{Ca}, \mathrm{Mg}$, and $\mathrm{P}$. Change from baseline in fecal ion excretion was evaluated by comparing the mean daily fecal excretion of the ion during the patiromer treatment week (Tuesday-Monday) versus the pretreatment week (Tuesday-Monday). Serum measurements were performed at the MedTox Laboratory (St. Paul, Minn., USA) and fecal analyses at the Battelle Toxicology Northwest (Richland, Wash., USA).

Electrocardiograms (ECGs) were performed in triplicate daily with the patient resting and prior to the morning patiromer dose. On HD days, triplicate ECGs were performed prior to HD, at the mid-dialysis time point, and $1 \mathrm{~h}$ post HD.

Patiromer, at a total daily dose of $12.6 \mathrm{~g} /$ day, was administered as $4.2 \mathrm{~g}$ TID with meals starting on the Monday morning of week 2.

\section{Statistics}

Originally, it was planned that $12-24$ patients would be assessed, but due to difficulty in the enrolling process, the study was stopped after assessment on 6 patients was completed. Due to the limited number of patients, the statistical inference testing results were conducted only for descriptive purposes. Descriptive statistics were summarized as mean \pm SE for continuous variables or as proportions for categorical variables unless specified otherwise. The protocol had a one-day run-in period on the diet, which is why the values on the first Monday of treatment was not analyzed; rather Tuesday-Monday values of the pre-patiromer week was compared to the Tuesday-Monday values of the patiromer treatment week. The changes on the corresponding days between pretreatment week and the patiromer treatment week in serum potassium and phosphate concentrations were analyzed by paired t test using SAS (version 9.4). The proportions of patients in each defined potassium range between the pre-treatment and the patiromer treatment week were analyzed by Fisher's exact test.

\section{Results}

Six patients enrolled and completed all study activities. One patient was enrolled in error with a screening $\mathrm{K}$ of $5.1 \mathrm{mEq} / \mathrm{l}$ but remained in the study. The mean $\pm \mathrm{SD}$ age was $50 \pm 4$ (range $44-55$ ) years. Five patients were male 
Table 1. Patient demographic and characteristic information

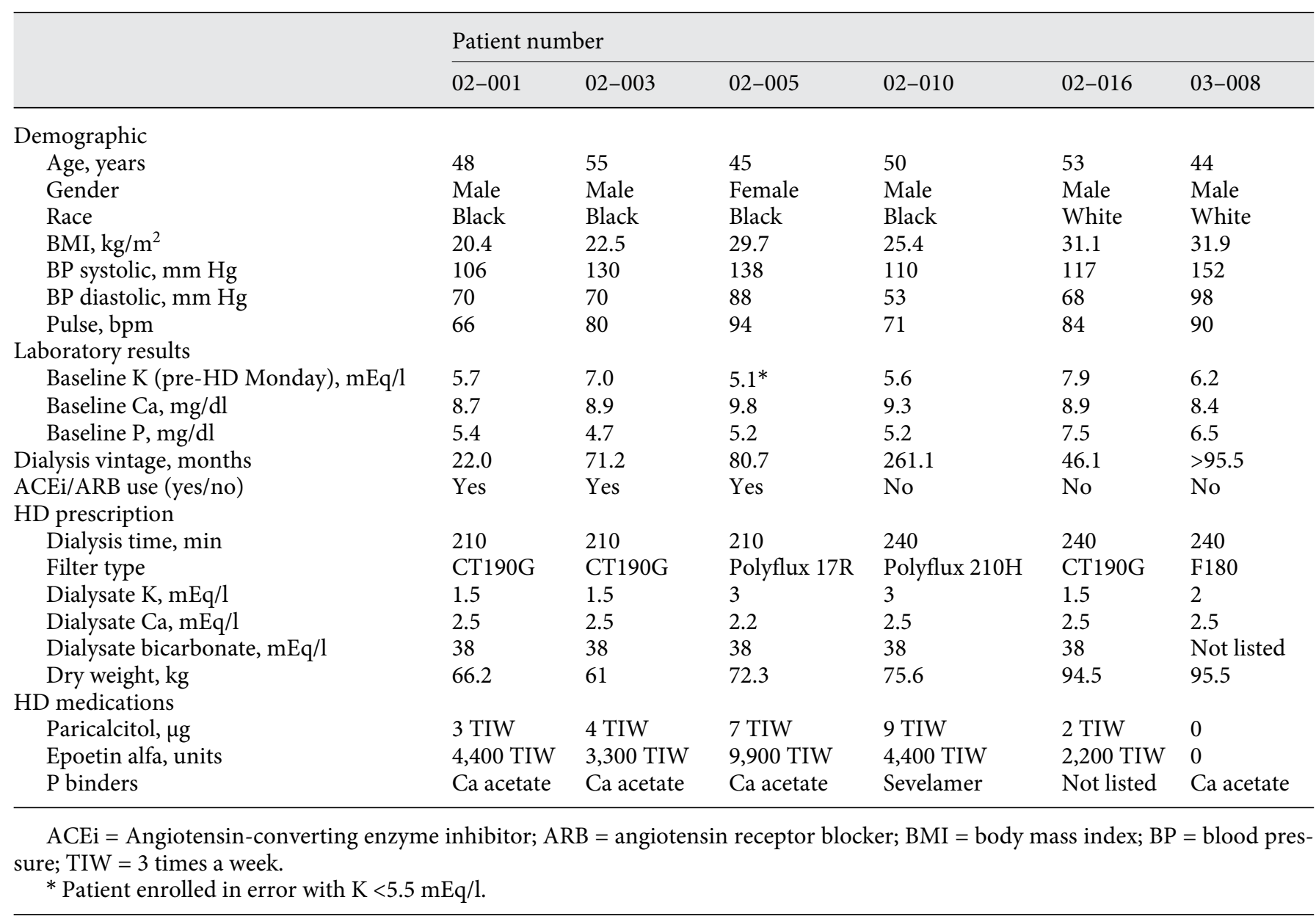

and 4 were black. Additional demographic information is shown in table 1. All 6 patients had extensive comorbid illnesses. Concomitant medical conditions present in all 6 patients at the time of the study in addition to end-stage renal disease (ESRD) included hyperkalemia, hyperparathyroidism, anemia, and hyperphosphatemia. In addition, 4 patients had concurrent hypertension. Patients were on multiple medications but were on stable doses for at least 15 days prior to the start of the study and throughout the study. Four patients received a beta-blocker, 2 an angiotensin-converting enzyme inhibitor, and 1 an angiotensin receptor blocker.

After 1 day of treatment, the serum $\mathrm{K}$ numerically decreased on patiromer versus the pretreatment week by $0.3 \pm 0.3 \mathrm{mEq} / \mathrm{l}(\mathrm{p}=\mathrm{ns} ; \mathrm{n}=6)$ when comparing the corresponding days of the week. The maximum difference was achieved at day 7 where the patiromer treatment serum $\mathrm{K}$ was $0.6 \pm 0.2 \mathrm{mEq} / \mathrm{l}$ lower than the value on the corresponding pretreatment day $(\mathrm{p}=0.009 ; \mathrm{n}=6$; fig. 1$)$. Online supplemental figure 1 (for all online suppl. material, see www.karger.com/ doi/10.1159/000451067) shows individual subjects' serum $\mathrm{K}$ values over time and demonstrates the variability of serum $\mathrm{K}$ in HD patients, while online supplemental figure 2 shows the average serum $\mathrm{K}$ values for the patiromer treatment week versus the pretreatment week by treatment day. During the pretreatment week, 69.0, 47.6 , and $11.9 \%$ of patients' daily serum $\mathrm{K}$ values were $\geq 5.5, \geq 6.0$, and $\geq 6.5 \mathrm{mEq} / \mathrm{l}$, respectively. These proportions were reduced to $38.1 \%(\mathrm{p}=0.008), 11.9 \%(\mathrm{p}<$ $0.001)$, and $2.4 \%(\mathrm{p}=0.2)$, respectively, on patiromer (fig. 2). While on patiromer, fecal K excretion increased by $359 \pm 113 \mathrm{mg} /$ day ( $58 \%$; equivalent to $64.4 \pm 20.3$ $\mathrm{mEq} /$ week) over the pretreatment week ( $\mathrm{p}=0.02$; range 110-739 mg/day), while fecal $\mathrm{Ca}$ increased by $1.3 \pm$ $0.1 \mathrm{~g} /$ day $(172 \% ; \mathrm{p}<0.01$; range $0.7-1.5 \mathrm{~g} /$ day $)$, fecal $\mathrm{Na}$ 
Fig. 1. Serum $K$ values over time during the pretreatment week and the patiromer treatment week. HD treatments are indicated by arrows. All patients were admitted to the research unit on a Sunday and started on the controlled diet Monday AM.
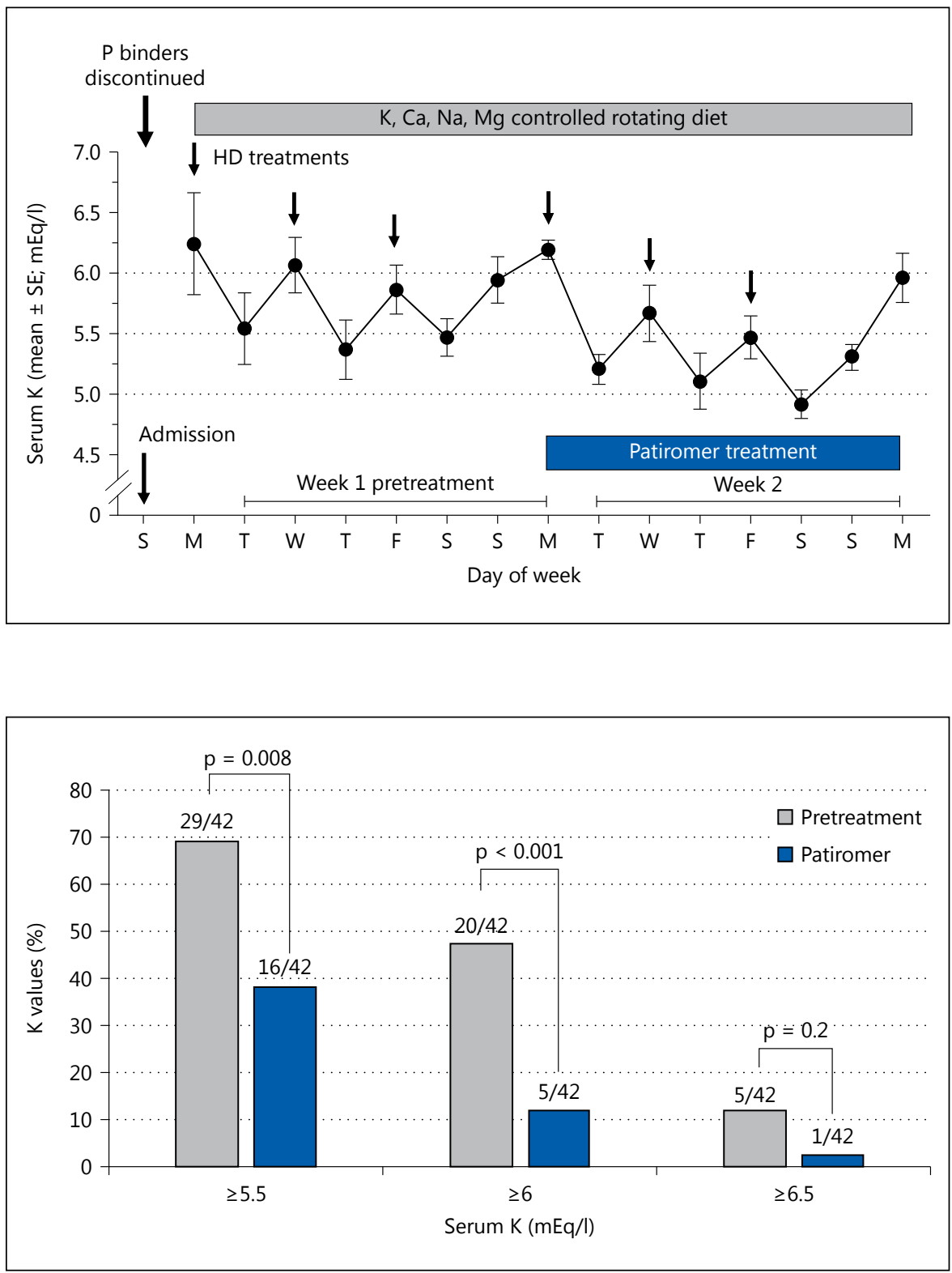

Fig. 2. The proportion of serum K concentrations above the corresponding $\mathrm{K}$ value. lytic serum P decreased from $7.0 \pm 0.5 \mathrm{mg} / \mathrm{dl}$ to $6.2 \pm 0.5$ $\mathrm{mg} / \mathrm{dl}(\mathrm{p}=0.04$; fig. 3 ). Online supplemental figure 3 demonstrates that ongoing exposure to patiromer increases the separation between the serum $P$ curves during the patiromer treatment versus the pre-patiromer treatment week.

\section{Safety}

No patient discontinued the study because of adverse events (AEs) and there were no serious AEs. One patient had a serum Ca as high as $11.0 \mathrm{mg} / \mathrm{dl}$ prior to patiromer treatment. On treatment with patiromer, the highest se- 
Fig. 3. Serum $\mathrm{Ca}$ and $\mathrm{P}$ over time in both the pretreatment week and during the patiromer treatment week. All P binders were stopped on the Sunday of admission. ${ }^{*} \mathrm{p}=$ 0.04 compared to the Monday $(\mathrm{M})$ value just prior to the start of the patiromer treatment week.

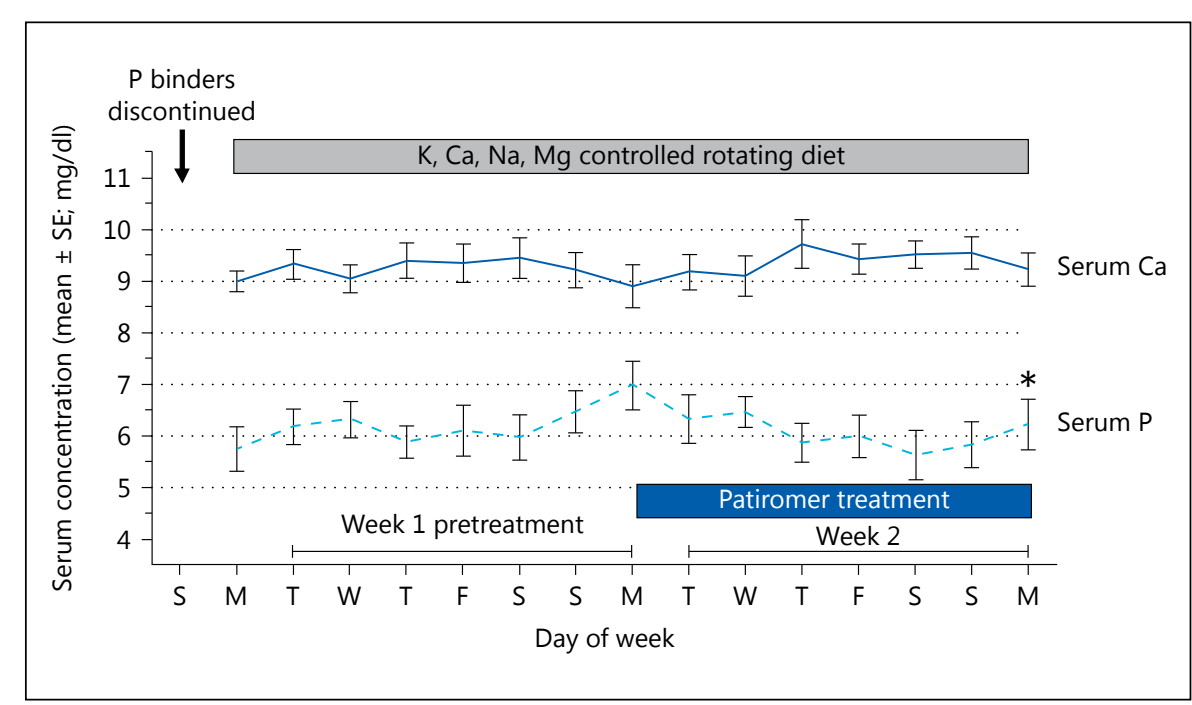

rum $\mathrm{Ca}$ in this patient was $10.8 \mathrm{mg} / \mathrm{dl}$. No patient had a serum Ca level during the patiromer treatment week that was above the levels observed in the pretreatment week. No patient developed a serum $\mathrm{K}<4.0 \mathrm{mEq} / \mathrm{l}$ on patiromer (lowest recorded serum $\mathrm{K}=4.2 \mathrm{mEq} / \mathrm{l}$ ). Serum $\mathrm{Mg}$ remained in the normal range and no patient developed clinical symptoms of hypomagnesemia (lowest serum $\mathrm{Mg}=1.3 \mathrm{mEq} / \mathrm{l})$. There were no individual clinically significant abnormal ECG findings and no AEs associated with ECG abnormalities at any time point during the study. However, all patients had abnormal ECG findings at multiple time points in the study that were judged not to be clinically significant and that are expected for individuals on $\mathrm{HD}$.

\section{Discussion}

In this metabolic study, daily administration of patiromer reduced the levels of both mean serum $\mathrm{K}$ and serum $\mathrm{P}$ in 6 hyperkalemic HD patients. Patiromer treatment decreased the proportion of days that patients were hyperkalemic compared with the pretreatment week. Despite the serum $\mathrm{K}$ variability in individual subjects, the differences in mean serum $\mathrm{K}$ between the treatment period and the pre-treatment period occurred early and were generally sustained throughout the treatment period, although the difference narrowed over the long interdialytic interval suggesting ongoing $\mathrm{K}$ redistribution or accumulation. A larger and longer-duration study allowing for dose titration is needed to further investigate the full effect of patiromer on serum $\mathrm{K}$ in this patient population. No patient discontinued the study for AEs and there were no serious AEs. Until recently, treatment options for hyperkalemia in $\mathrm{HD}$ patients were limited to dietary K restriction, low-K dialysate, additional dialysis, or intermittent SPS. All of these options have significant limitations in adequately dialyzed patients. Lower dialysate $\mathrm{K}$ concentrations increase the risk of arrhythmias or sudden death $[12,13]$ and higher sodium intake has been associated with increased interdialytic weight gain and mortality [14]. Furthermore, use of SPS has been associated with increased interdialytic weight gain and higher serum phosphate, bicarbonate and sodium concentrations in HD patients [15].

The finding from this study provides preliminary evidence that daily patiromer, even when administered at a low dose (as discussed below), can remove more $\mathrm{K}$ than what is achieved by lowering the dialysate $\mathrm{K}$ by $1 \mathrm{mEq} / \mathrm{l}$ for 3 treatments/week [16] and suggests that patiromer may be an alternate and potentially safer therapy than lowering the dialysate $\mathrm{K}$ concentration for dialysis patients with hyperkalemia. As $\mathrm{K}$ normally fluctuates in patients with CKD [2], the possibility of minimizing these fluctuations and providing safer dialysis with patiromer deserves further study. Studies using patiromer in conjunction with a more physiologic $\mathrm{K}$ dialysate are also needed to determine if arrhythmic events during and post dialysis can be decreased by following such an approach.

In this study, $\mathrm{P}$ binders were stopped at the time of admission to the clinical research center and serum $P$ levels were increased during the pre-treatment week. When patiromer was given with meals instead of the phosphate binder, the serum $\mathrm{P}$ level decreased. The numeric increase in stool $\mathrm{P}$ is supportive of a potentially clinically 
meaningful effect. The reduction in serum $\mathrm{P}$ level seen in these patients with the increasing separation with ongoing treatment (online suppl. fig. 3 ) is in agreement with earlier studies in healthy volunteers showing that patiromer decreased gastrointestinal phosphate absorption as measured by a decrease in urine $\mathrm{P}$ on a controlled diet [17]. The reduction in serum $P$ level seen in this study may be due to the gastrointestinal binding of $\mathrm{P}$ by the $\mathrm{Ca}$ released from patiromer, leading to less gastrointestinal $\mathrm{P}$ absorption.

The mean serum Ca level remained within the normal range in these ESRD patients on patiromer. The 1 patient with mild hypercalcemia was hypercalcemic during the pretreatment period and the peak serum Ca level in this patient on patiromer was lower than the peak Ca level during the pretreatment period. The increase in stool Ca during the patiromer treatment week demonstrates that the vast majority of the $\mathrm{Ca}$ in patiromer appears in the stool bound to the polymer as previously reported [10]. This is consistent with the understanding that the main site of Ca-K exchange is in the colon where the efficiency of Ca absorption is minimal [18]. This is also in agreement with studies in healthy controls, where changes in urine calcium were used as a measure of intestinal ion absorption, which demonstrated that about $73 \mathrm{mg}$ of calcium is absorbed from a daily dose of $25.2 \mathrm{~g}$ dose of patiromer [17].

The finding that the levels of stool $\mathrm{Na}$ and $\mathrm{Mg}$ increased, support data that patiromer binds $\mathrm{Na}$ and $\mathrm{Mg}$ within the gastrointestinal tract as measured by a decrease in these ions in the urine excreted by healthy adults who are given patiromer [17]. The changes in stool $\mathrm{Na}$ are such that it suggests that patiromer may bind $\mathrm{Na}$ in the gastrointestinal tract as previously reported [17]. Although numerically small, decreased $\mathrm{Na}$ absorption could be beneficial in this patient population where interdialytic weight gain and ultrafiltration volume have been associated with adverse outcomes $[19,20]$. While the level of serum $\mathrm{Mg}$ is often within the normal range in $\mathrm{HD}$, some patients have increased serum levels [21]. While the risk or benefits of increased serum $\mathrm{Mg}$ in $\mathrm{HD}$ patients is controversial [22], these findings suggest that serum $\mathrm{Mg}$ should be monitored in HD patients treated with patiromer [5].

This study has a few important limitations. Most notably is the small sample size $(n=6)$ of this study with short treatment duration. In addition, serum potassium concentrations vary within a patient. Larger and a longerduration studies with a randomized controlled design in HD patients are needed to confirm the findings in this study and to ensure tolerability in this patient population. Another limitation of the current study was the non-randomization of the control and treatment weeks. The potential bias of this methodology was somewhat limited by the use of the clinical research center. An important strength of this study is the controlled dietary conditions, along with the consistency of its results (e.g., a decrease in serum $\mathrm{K}$ accompanied by an increase in stool $\mathrm{K}$, the latter most probably ruling out any dietary confounding factor). Furthermore, only 1 dose strength of patiromer was tested in this study. The dose tested, $12.6 \mathrm{~g} /$ day, is half of the FDA-approved maximum dosage. While the dose tested limits our ability to assess tolerability of higher doses in this population, it suggests that greater $\mathrm{K}$ and $\mathrm{P}$ removal could be achieved with greater doses of patiromer. The increase toward baseline in the serum K on the Monday after the last dose of patiromer probably reflects the ongoing $\mathrm{K}$ burden in these patients and highlights the need for studies of longer duration with potential dose escalations. Finally, in this study, patiromer was administered 3 times per day and all $P$ binders were stopped on admission. As patiromer is approved for once-per-day dosing [5], the optimal use of $\mathrm{P}$ binders in conjunction with patiromer treatment needs further study. This study suggests that $\mathrm{P}$ binders used 2 times per day with meals along with patiromer with the third meal might be a reasonable strategy to maintain adequate $\mathrm{P}$ control while allowing for safe and effective lowering of $\mathrm{K}$ levels.

In conclusion, the ability of patiromer to decrease serum $\mathrm{K}$ and $\mathrm{P}$ levels and increase fecal $\mathrm{K}$, and potentially fecal $\mathrm{P}$ and $\mathrm{Na}$ in $\mathrm{HD}$ patients suggests that patiromer may have beneficial effects on multiple aspects of abnormal mineral metabolism in HD patients. The unique ability of patiromer to both lower serum $\mathrm{K}$ and bind gastrointestinal $\mathrm{P}$, without increasing the daily $\mathrm{Na}$ load to $\mathrm{HD}$ patients, suggests it could play an important role in the care of HD patients.

\section{Acknowledgment}

Editorial assistance in regard to figure design and drawing, reference retrieval and formatting was provided by AlphaBioCom, King of Prussia, PA, funded by Relypsa Inc.

\section{Disclosure Statement}

D.A.B. reports personal fees from Relypsa, Amgen, Sanofi, Aventis/Genzyme, Tricida, Fresenius Medical Care, and OPKO Health; he also reports stock options in Relypsa and Tricida. P.R. 
reports personal fees from Relypsa, Astra-Zeneca, Novartis, Stealth peptides, Vifor-Fresenius Medical Care Renal Pharma; he is cofounder of CardioRenal. D.M.S., W.W.B., and J.Y. are employees of Relypsa. G.A.B. reports personal fees from Relypsa. C.S.W. has nothing to disclose. R.A. reports personal fees from Relypsa and ZS Pharma.

\section{Funding}

Funded by Relypsa, Inc.

\section{References}

1 Kovesdy CP, Regidor DL, Mehrotra R, Jing J, McAllister CJ, Greenland S, Kopple JD, Kalantar-Zadeh K: Serum and dialysate potassium concentrations and survival in hemodialysis patients. Clin J Am Soc Nephrol 2007;2: 999-1007.

2 Bushinsky D, Mayo M, Garza D, Stasiv Y, Wilson DJ, Du Mond C, Berman L, Epstein M: Wide range in variation in serum potassium in hyperkalemic patients with CKD; response to a fixed $60 \mathrm{mEq}$ potassium diet. Abstract. J Am Soc Nephrol 2015;26:845A-846A.

3 Lowrie EG, Lew NL: Death risk in hemodialysis patients: the predictive value of commonly measured variables and an evaluation of death rate differences between facilities. Am J Kidney Dis 1990;15:458-482.

4 Foley RN, Gilbertson DT, Murray T, Collins AJ: Long interdialytic interval and mortality among patients receiving hemodialysis. $\mathrm{N}$ Engl J Med 2011;365:1099-1107.

5 Veltassa (Patiromer) for Oral Suspension (Package Insert). Relypsa, Redwood City, 2015.

6 Weir MR, Bakris GL, Bushinsky DA, Mayo MR, Garza D, Stasiv Y, Wittes J, ChristSchmidt H, Berman L, Pitt B; OPAL-HK Investigators: Patiromer in patients with kidney disease and hyperkalemia receiving RAAS inhibitors. N Engl J Med 2015;372:211-221.

7 Bakris GL, Pitt B, Weir MR, Freeman MW, Mayo MR, Garza D, Stasiv Y, Zawadzki R, Berman L, Bushinsky DA; AMETHYST-DN Investigators: Effect of patiromer on serum potassium level in patients with hyperkalemia and diabetic kidney disease: the AMETHYSTDN randomized clinical trial. JAMA 2015; 314:151-161.
8 Pitt B, Bakris GL, Bushinsky DA, Garza D, Mayo MR, Stasiv Y, Christ-Schmidt H, Berman L, Weir MR: Effect of patiromer on reducing serum potassium and preventing recurrent hyperkalaemia in patients with heart failure and chronic kidney disease on RAAS inhibitors. Eur J Heart Fail 2015;17:10571065.

9 Agarwal R, Afzalpurkar R, Fordtran JS: Pathophysiology of potassium absorption and secretion by the human intestine. Gastroenterology 1994;107:548-571.

10 Li L, Harrison SD, Cope MJ, Park C, Lee L, Salaymeh F, Madsen D, Benton WW, Berman L, Buysse J: Mechanism of action and pharmacology of patiromer, a nonabsorbed crosslinked polymer that lowers serum potassium concentration in patients with hyperkalemia. J Cardiovasc Pharmacol Ther 2016;21:456465.

11 Wrong O, Metcalfe-Gibson A: The electrolyte content of faeces. Proc R Soc Med 1965;58: 1007-1009.

12 Jadoul M, Thumma J, Fuller DS, Tentori F, Li Y, Morgenstern H, Mendelssohn D, Tomo T, Ethier J, Port F, Robinson BM: Modifiable practices associated with sudden death among hemodialysis patients in the Dialysis Outcomes and Practice Patterns Study. Clin J Am Soc Nephrol 2012;7:765-774.

13 Pun PH, Lehrich RW, Honeycutt EF, Herzog CA, Middleton JP: Modifiable risk factors associated with sudden cardiac arrest within hemodialysis clinics. Kidney Int 2011;79:218227.

14 Mc Causland FR, Waikar SS, Brunelli SM: Increased dietary sodium is independently associated with greater mortality among prevalent hemodialysis patients. Kidney Int 2012; 82:204-211.
15 Jadoul M, Karaboyas A, Goodkin DA, Tentori F, Li Y, Labriola L, Robinson BM: Potassium-binding resins: associations with serum chemistries and interdialytic weight gain in hemodialysis patients. Am J Nephrol 2014;39: 252-259.

16 Hou S, McElroy PA, Nootens J, Beach M: Safety and efficacy of low-potassium dialysate. Am J Kidney Dis 1989;13:137-143.

17 Bushinsky DA, Spiegel DM, Gross C, Benton WW, Fogli J, Hill Gallant KM, Du Mond C, Block GA, Weir MR, Pitt B: Effect of patiromer on urinary ion excretion in healthy adults. Clin J Am Soc Nephrol 2016;11:17691776.

18 Bronner F, Pansu D: Nutritional aspects of calcium absorption. J Nutr 1999;129:9-12.

19 Flythe JE, Curhan GC, Brunelli SM: Disentangling the ultrafiltration rate-mortality association: the respective roles of session length and weight gain. Clin J Am Soc Nephrol 2013; 8:1151-1161.

20 Kalantar-Zadeh K, Regidor DL, Kovesdy CP, Van Wyck D, Bunnapradist S, Horwich TB, Fonarow GC: Fluid retention is associated with cardiovascular mortality in patients undergoing long-term hemodialysis. Circulation 2009;119:671-679.

21 Li L, Streja E, Rhee CM, Mehrotra R, Soohoo M, Brunelli SM, Kovesdy CP, Kalantar-Zadeh $\mathrm{K}$ : Hypomagnesemia and mortality in incident hemodialysis patients. Am J Kidney Dis 2015;66:1047-1055.

22 Spiegel DM: Magnesium in chronic kidney disease: unanswered questions. Blood Purif 2011;31:172-176. 